\title{
FORMAS DE GESTÃO: O DESAFIO DA MUDANÇA
}

ARTIGOS

*Robert Henry Srour

A mudança organizacional não é um ato indeterminado, mas resultado de um exercício político.

The organizational change is not an indetermined act, but a political exercise result.

PALAVRAS-CHAVE:

Formas de gestão, relacões de

poder, ideologias politicas,

ideologias económicas, mu-

danças organizacionais.

\section{KEY WORDS:}

Management patterns, power

relations, politic ideologies,

economic ideologies, business

changes.

*Doutor em Sociologia pela USP, Diretor Geral da IMS Serviços Científicos. 
As empresas, como outras tantas coletividades - nações ou vilarejos, cidades ou acampamentos de garimpeiros, comunas ou aldeias de pescadores, vilas ou malocas de índios - , têm necessidade inadiável de regular suas atividades. Ademais, as organizações sociais não são meras coleções de indivíduos, mas entidades com vida e dinâmica próprias, que transcendem as consciências e os interesses particulares de seus membros.

A forma de regular as atividades de uma organização não constitui um exercício de livre-arbítrio. Dá-se num campo de possibilidades balizadas pelas relações de propriedade, ou melhor, opera segundo a lógica que o sistema de apropriação de excedentes define.

Entidades baseadas em relações de propriedade corporativa - sindicatos, fundações, associações profissionais, partidos políticos totalitários, a Igreja Católica, empresas estatais à maneira soviética, fascista ou nazista - realizam a apropriação do sobreproduto (valor excedente gerado) através da intervenção de mecanismos políticos ou simbólicos. As cúpulas sindicais ou clericais, por exemplo, têm acesso diferencial aos excedentes em função das posições hierárquicas ocupadas. Nessas condições precisas, as formas de regular as atividades coletivas (ou o exercício do poder) propendem a ser autoritárias ou totalitárias, em função de tendências imanentes à oligarquização (lei de ferro de Michels) e justamente por ser corporativa a propriedade.

Em contrapartida, entidades baseadas em relações de propriedade capitalista as empresas capitalistas, de propriedade plena e individual - possuem uma lógica essencialmente econômica. É válido afirmar que as empresas capitalistas encontram sua razão de ser e seus mecanismos de reprodução na apropriação privada de excedentes econômicos (por parte dos quotistas ou acionistas) e ordenam cada uma de suas atividades em função desse motor. Suas formas de regular as atividades tendem a ser autoritárias (monarquias absolutistas ou presidencialismos autocráticos), embora contemporaneamente evoluam, sob pressões do ambiente externo e de seus gestores e trabalhadores, para formas liberais de exercício do poder.
De forma similar, as lógicas que animam entidades cooperativistas, feudais, comunais, latifundiárias, patriarcais (pequena propriedade familiar), patrimoniais, ou as de tipo comunitário (primitivas, gentílicas ou anarquistas), são radicalmente diversas, uma vez que seu modo de produzir bens ou serviços e seu modo de apropriarse do sobreproduto são absolutamente distintos. ${ }^{1}$

Assim sendo, a regulação de atividades coletivas, que é uma operação eminentemente política, não se dá a esmo. Captar a lógica que traveja uma organização qualquer significa abrir o leque das possíveis formas de gestão que são consentâneas a essa lógica. O conceito de forma de gestão pode ser definido como a articulação de relações específicas de poder com uma ideologia política hegemônica, sob a égide determinante de relações de propriedade dadas.

Essa ferramenta conceitual parece útil para a consecução de mudanças organizacionais competentes. Com efeito, se forem utilizadas as mesmas "receitas" para reestruturar empresas estatais e empresas privadas, órgãos públicos da administração direta e cooperativas, entidades religiosas e empresas familiares, associações profissionais e empreendimentos de trabalhadores autônomos, sindicatos e empresas transnacionais, organismos internacionais e bolsas de valores etc., os riscos de tornar a intervenção organizacional inoperante, senão caótica, são consideráveis. Afinal, no lusco-fusco da noite anunciada, todos os gatos parecem pardos. Contudo, seria o bastante para considerá-los como tais?

Entre consultores organizacionais, a lembrança das muitas desilusões e dos inúmeros fracassos que resultaram das tentativas de levar a cabo um duradouro "desenvolvimento organizacional" é recorrente. Citam-se empresas que testam todas as modas à procura de novas panacéias; indicam-se empresas que contratam todos os gurus de plantão, ansiando por catecismos salvacionistas, e perdem-se de vista empresas que treinam seqüencialmente seu corpo gerencial nos mais "recentes achados" da literatura administrativa e que, no mais das vezes, colhem happenings.

Dito de outro modo: prevalece entre nós o costume de misturar dispositivos con-
1. SROUR, R. H. Modos problemática. Rio de Janeiro: Graal, 1978. 
ceituais, tal como se faz com os ingredientes de uma salada, sem percepção de suas diversas origens ou vinculações teóricas. Daí o empiricismo míope e as intervenções organizacionais de "bom senso". Faz-se da disciplina administrativa, no mais das vezes, um estuário das mais variadas escolas ou correntes da Sociologia e da Ciência Política, da Psicologia e da Psicanálise, da Antropologia e da Economia Política, para não nomear outras fontes menos nobres. E derrapa-se para o gargalo do senso comum ou para o exercício prescritivo da adivinhação.

Como escapar disso? Pela humildade intelectual em reconhecer que existem "arquiteturas" teóricas diferenciadas, sistemas ou matrizes cujos travejamentos são essencialmente contraditórios. Daí a necessidade de realizar um esforço de clarificação da matriz científica e da postura epistemológica utilizadas. Daí o imperativo de operar uma verificação das compatibilidades e das congruências conceituais. Por exemplo, no campo das Ciências Sociais, existem, grosso modo, uma abordagem weberiana-compreensiva, uma abordagem durkheimiana-positivista e uma abordagem marxista-dialética (ainda que várias leituras de Marx possam ser feitas - uma funcionalista-economicista, outra historicista-humanista e outra ainda estruturalista-althusseriana), cujas incompatibilidades são notórias. Por via de conseqüência, a propriar-se impunemente de conceitos específicos a cada matriz ou a cada leitura, e baralhá-los sem mais, leva à formulação de discursos cujo cientificismo torna-se discutível.

Entretanto, se o pesquisador não quiser emparedar-se em ortodoxia alguma, cumpre-lhe pelo menos reconhecer as linhas demarcatórias que distinguem as matrizes teóricas para, logo em seguida, empenharse em definir com rigor os conceitos utilizados. Assim, quando empréstimos entre matrizes forem indispensáveis, cabe-lhe ainda esforçar-se para "descontextualizar" os conceitos e adaptá-los ao dispositivo teórico que adota. Parece vital, portanto, que o pesquisador procure manter congruência entre suas diversas ferramentas de trabalho. Arriscadíssimo (como costu- que resta às empresas brasileiras? Mudar a forma de gestão, que as ordena ou enfrentar em absoluta desigualdade de condições a exposição à concorrência externa?

ma acontecer) seria operar ao sabor dos encontros e desencontros conceituais, numa postura que apenas a ingenuidade desculpa, mas que a realidade não perdoa.

Em função dessas constatações, o presente trabalho pretende identificar as formas de gestão das empresas capitalistas (suas possibilidades históricas) a partir de uma matriz histórico-estrutural, cuja base epistemológica é dialética. Seu intuito objetiva instrumentar as mudanças organizacionais que o momento atual impõe às empresas brasileiras.

\section{POR QUE MUDAR?}

Nos anos 90, as empresas brasileiras passaram a viver um dilema dilacerante: reestruturar-se ou perecer. A razão mais evidente disso remete à "Segunda Abertura dos Portos" que está em curso e que está apanhando boa parte delas em franca desvantagem tecnológica - quer em termos de processo produtivo, quer em termos de gestão administrativa - diante das empresas estrangeiras multinacionais, internacionais, globais ou transnacionais. ${ }^{2}$

Mas por que integrar-se ao novo sistema mundial competitivo nessas condições? Porque o padrão de desenvolvimento (Estado-produtor e substituição universal de importações), que presidiu ao domínio do capitalismo no Brasil após a Segunda Guerra Mundial, exauriu-se. Calcado na chamada Segunda Revolução Industrial, de base técnica eletromecânica, o sistema econômico brasileiro está sendo questionado nas suas entranhas pela Terceira Revolução Científico-Técnica, de base técnica microeletrônica. ${ }^{3}$

Alavancado pelo Estado que lhe for-
2. BARTLETT, A.C., GHOSHALL, S. Gerenciando empresas no exterior - a solução transnacional. Sāo Paulo: Makron Books, 1992.

3. SANTOS, T. dos. Economia mundial, integração regional e desenvolvimento sustentável. Petrópolis: Vozes, 1993. 
neceu recursos e proteções, o setor privado da economia brasileira não encontra mais no parceiro de todas as horas senão um aparelho em situação falimentar. Com efeito, o Estado se debate, em desespero, entre o peso do serviço da dívida externa e o sorvedouro da dívida interna. $E$ isso tudo se vê potencializado pelas empresas estatais que se desgarraram há tempo de suas responsabilidades públicas, numa autonomização burocrática cujas conseqüências corporativistas jamais poderiam ser elididas.

Em outros termos, o capitalismo brasileiro configurou-se como cartorial, protecionista e oligopolista. Assumiu as feições clássicas do que poderíamos denominar de "capitalismo excludente": um sistema cujo crescimento beneficia parcelas ínfimas da população, enquanto marginaliza de seus benefícios e converte em desvalidos o grosso do restante. Um sistema que confronta, de um lado, uma "elite cidadã" que desfruta efetivamente daquilo que o conceito pressupõe (direitos e acessos plenos à qualidade de vida) e, de outro, uma "massa de súditos", destituídos em termos concretos de direitos sociais, políticos e, por que não dizê-lo, de direitos civis. São esses "súditos" os excluídos do Brasil moderno, os que constituem o lado de lá do apartheid social, os que passam ao largo do mercado de consumo e do mercado de trabalho formal, vegetando na economia informal, no desemprego crônico e no lumpesinato.

Tal tipo de capitalismo, que vigorou em muitas outras partes do planeta até as últimas décadas, depara-se agora com as novas tendências do "capitalismo social" que ganha músculos no Primeiro Mundo e cuja configuração prenuncia-se como competitiva, integracionista e transnacional. Um capitalismo que se assenta sobre a chamada Terceira Revolução Industrial, tradução complexa de várias outras revoluções: a das novas tecnologias, a da informação e das telecomunicações, a da qualidade, a da produção flexível e enxuta, a da gestão participativa (co-responsabilidade dos gestores e dos trabalhadores no processo de trabalho), a do marketing e da centralidade do cliente na conformação estratégica das empresas, a da base técnica microeletrônica com automação e robotização, a da ciência e da tecnologia como fontes-chave de geração de valor via trabalho mental.

Trata-se de um capitalismo que altera radicalmente as relações de trabalho, devolvendo aos trabalhadores parte do controle técnico sobre o processo de produção - apropriação real de seus instrumentos de trabalho, graças à intensa qualificação e à prévia escolarização. Mas, sobretudo, trata-se de um capitalismo que prioriza os stakeholders (contrapartes do ambiente empresarial) em relação aos shareholders (acionistas, proprietários), acrescentando à lógica do lucro as determinações da responsabilidade social ou da função ética e social da propriedade. Tratase, por fim, de um sistema que distribui parcela expressiva dos excedentes gerados para a população trabalhadora, através de serviços públicos eficientes e acessíveis (salários indiretos) e através da participação nos resultados empresariais. Para tanto, basta lembrar as experiências socialdemocratas européias (economias sociais de mercado), ainda que estas estejam se redefinindo para extirparem de seu seio os excessos assistencialistas.

Naturalmente, é preciso salientá-lo, tal transformação estrutural não ocorreu por mera "evolução natural", nem por uma crise de altruísmo que repentinamente tenha assaltado a consciência empresarial. Decorreu de embates políticos e sindicais travados ao longo de decênios, que converteram as relações sociais autoritárias em relações sociais liberais. A saber: os enfrentamentos sociais facultaram a construção de uma cidadania vigilante e de sociedades civis poderosas, capazes de retaliar organizações "selvagens" ou socialmente irresponsáveis.

No Brasil, todavia, o sonho de um capitalismo nacional autônomo (se não autárquico), ancorado na substituição das importações e estribado no protecionismo das reservas de mercado e nas tarifas aduaneiras proibitivas, revelou-se empiricamente frágil e economicamente insustentável. Não desfrutou, por conseguinte, de uma sociedade civil mobilizada em torno de uma utopia democrática.

O modelo, aliás, sempre esteve a reboque da tutela dirigista do Estado. Sofreu a pane de seus motores, nos anos 80 , com o retraimento das fontes de financiamento externo - quer das inversões de capitais 
estrangeiros, quer dos empréstimos -, e ameaçou pegar fogo - hiperinflação com o concomitante esgotamento dos mecanismos de uma moedagem descontrolada e da taxação perversa do "imposto inflacionário".

Em conseqüência, a infra-estrutura de apoio para as operações empresariais cujos investimentos exigem longo tempo de maturação (tais como hidrelétricas, malha rodoviária, ferrovias, redes de telefonia) e os programas e equipamentos sociais de precípua vocação pública (previdência social, obras de saneamento básico, segurança e justiça, sistemas educacional e de saúde) degradaram-se de forma crítica, detonando sérias dificuldades operacionais para o sistema produtivo.

Nessa esteira, e como se um dique tivesse sido rompido, a efetividade empresarial foi revisitada. Saltaram à vista os efeitos negativos da dependência umbilical entre um volume significativo de grandes empreendimentos privados e as inversões públicas. Tais laços, às vezes espúrios, podem ser rastreados nas décadas de subsídios, perdões de dividas, isençôes fiscais, financiamentos a juros preferenciais, controles de preços, tarifas alfandegárias, reservas de mercado e larga socialização dos prejuízos. De maneira que, se forem somados a esses vetores o empreguismo endêmico que grassou nas três esferas governamentais, o corporativismo das empresas estatais e a proverbial ineficiência dos órgãos da administração direta, desvendaria-se a configuração que assumiu o capitalismo no Brasil.

Um capitalismo cartorial, sem dúvida, que autoriza a convivência simbiótica entre setores privados e setores estatais (cartórios empresariais) e que ceva outros tantos cartórios corporativos, ainda que sindicais, fontes de abusos particularistas e de arroubos populistas. Um capitalismo sem risco, atrelado aos interesses patrimonialistas das elites e desprovido dos instrumentos indispensáveis para a competição em mercados abertos. Um sistema econômico que magnificou a hegemonia dos oligopólios e dos cartéis e que se enredou nas malhas de um "Es- tado-empresário" mastodôntico, cujas burocracias obtiveram uma autonomia pronunciada em relação à sociedade civil. Um capitalismo, em suma, à mercê de um aparelho estatal fortemente intervencionista e minuciosamente regulamentador.

O Estado faliu na segunda metade dos anos 80 e questionou em seu cerne, do ponto de vista estrutural, o tipo de capitalismo implantado no Brasil. Assim é que o tutor, provedor e interventor está hoje exangue. capitalismo social se assenta sobré una Revoluçáo TécricoCientílica, tradução complexa de váilias outras revoluções.

\section{O DILEMA DA SOBREVIVÊNCIA}

O que resta às empresas brasileiras? Viver sem medo o ponto de inflexão desse novo período histórico ou definhar e agonizar em fogo brando. Vale dizer, mudar a forma de gestão que as ordena ou enfrentar em absoluta desigualdade de condições a exposição à concorrência externa. Porque a abertura da economia brasileira ao mercado internacional é o reconhecimento do processo de globalização em curso (ainda que se constituam blocos regionais numa intrincada estratégia de protecionismo negociado). E é também a percepção consciente, por parte de forças hegemônicas na sociedade civil, que o antigo padrão de desenvolvimento, de caráter nacional-populista, tornou-se insustentável. Sem aporte de recursos externos e de tecnologia de ponta, o país poderia resumir-se a abrigar setores poluidores e a patinar numa economia produtora de matérias-primas te de manufaturados de lecnologia intermediária.

Parece sábio, por via de conseqüência, que as empresas brasileiras procurem desenvolver um diferencial de competência que lhes assegure competitividade inter- 
nacional em determinados nichos. Sem o que, as alternativas que lhes restam seriam: definhar; converter-se em montadoras de kits importados ou assumir o papel de entrepostos comerciais.

Nessas condições, a sobrevivência das empresas brasileiras passa por uma indispensável reestruturação, isto é, desde logo, pela inteligibilidade das formas de gestão e dos delicados processos da mudança organizacional. Não se trata, é claro, de mimetizar, de maneira conformista, padrões organizacionais primeiro-mundistas, mas de dispor de um quadro de referência consistente do ponto de vista científico e empiricamente fundado, que viabilize reestruturações a um só tempo factíveis e adequadas ao contexto brasileiro.

O que não se pode fazer, portanto, sucumbindo a rompantes bem ao gosto das improvisações imediatistas de alguns empresários brasileiros, é montar um Frankenstein de formas de gestão colocar um motor Fórmula 1, por exemplo, num carro de passeio brasileiro. Ou querer passar diretamente de uma forma de gestão a outra, sem construir as transições pertinentes. Porque não se vai impunemente de uma forma de gestão ortodoxa (figurativamente, uma repartição pública) para uma forma de gestão reformista (um centro de pesquisa, por exemplo). Há que se passar, em tese, por formas de gestão intermediárias como a clássica (figurativamente, uma loja de departamentos) e a forma de gestão pluralista (uma agência de publicidade, por exemplo).

Dificilmente as organizações se prestam a saltos revolucionários, a não ser que, num curto-circuito simultâneo, sejam transformadas as relações de propriedade. E a passagem de uma forma de gestão à outra, no marco das mesmas relações de propriedade, pressupõe um complexo esforço de "construção" de novas relações de poder, conjugadas com novas relações de saber. Trata-se de reformas políticas que afetam interesses cristalizados e de inovações culturais que implodem velhas convicções, o que não é pouco. Por isso a necessidade não só de planejamento profissional da transição, mas de uma estratégia gradual que consolide os terrenos "conquistados", articule os interesses e legitime as inovações. Caso con- trário, as transformações podem sofrer inúmeros percalços, resistências subterrâneas e graves sabotagens.

Em outras palavras, cabe partir da realidade presente das empresas (Quais são nossas reais relações de poder? Qual a nossa cultura organizacional modal?) e situar as altas direções diante de um leque de alternativas gestionárias que possam ser alcançadas quer num horizonte imediato, quer num horizonte mediato. Tais precauções facultarão uma análise de custo/benefício, não só em termos econômicos, mas também em termos de imagem e de viabilização política da passagem de um estado $X$ para um estado $Y$. De outra parte, a escolha informada de uma nova forma de gestão deveria assegurar, por princípio, maior efetividade organizacional e, sobretudo, maior competitividade empresarial.

De sorte que muito ganhariam as empresas que, bússola na mão, conseguirem refletir sobre as próprias virtualidades.

\section{A EMPRESA COMO MICROCOSMO SOCIAL}

O espaço interno das empresas não é neutro: responde a variadas determinações de ordem econômica, política e simbólica.

De fato, ao constituir-se como unidade produtiva de bens e serviços, geradora e distribuidora de excedentes econômicos, a empresa atualiza um sistema de apropriações (relações de propriedade) e inscreve-se num ambiente externo hostil - o "mercado" - em que muitas contrapartes a pressionam (clientes, fornecedores, prestadores de serviços, bancos, sindicatos, mídia e demais entidades da sociedade civil, órgãos públicos, concorrentes atuais e novos entrantes, comunidade circunvizinha).

Ao constituir-se, ao mesmo tempo, como entidade política, tomadora de decisões que afetam diversas forças sociais, a empresa abriga simultaneamente um sistema de interesses (relações de poder) e funciona como "arena" em que contrapartes externas e internas (proprietários, gestores e trabalhadores) se chocam e alocam diferencialmente o mando e, obviamente, os resultados.

Finalmente, ao constituir-se, de modo concomitante e inextricável, como agência 
ideológica, difusora de discursos e mensagens, a empresa incorpora um sistema de referências (relações de saber) e opera como "palco" em que as contrapartes em confronto sofrem um mútuo processo de inculcação cultural que procura responder às exigências de adaptação externa e de coesão interna.

As divergências que polarizam os agentes organizacionais não podem ser consideradas como gratuitas nem podem ser reduzidas a idiossincrasias de caráter psicológico. São, isso sim, efeitos das posições sociais que esses agentes ocupam no espaço empresarial, além de derivarem dos interesses diferenciais que as clivagens da sociedade inclusiva provocam. Quer dizer, toda organização incorpora inúmeros "recortes" que existem no espaço social, com suas múltiplas hierarquias e diferenciações: categorias sociais (coletividades que se distinguem por estatutos sociais diferenciados gêneros, raças, ocupações, gerações, etnias, origens regionais, preferências sexuais, condições de capacidade etc.) e classes sociais (posições contraditórias na ocupação, relação econômica com os meios de produção).

Isto torna o gerenciamento dos interesses um fenômeno altamente relevante para implementar decisões (donde a séria questão da legitimidade) e, sobretudo, converte-o em pedra de toque para viabilizar mudanças (daí a delicada questão da "costura dos interesses").

\section{AS FORMAS DE PRODUÇÃO COMO FATORES DETERMINANTES}

É certo que toda forma de gestão constitui uma articulação política de relações de poder (mando e obediência), assim como toda forma de produção constitui uma articulação econômica de relações de produção (propriedade e trabalho) e toda forma de pensamento constitui uma articulação simbólica de relações de saber (inculcação e justificação).

Todavia, entre essas diferentes articulações existem compatibilidades e determinações estruturais. Por exemplo: formas de gestão autogestionárias, à semelhança dos coletivos de trabalho que são o mutirão no Brasil rural ou as comunidades anarquistas, remetem a formas de produção comunitárias. E essas formas de gestão não são compatíveis com formas de produção capitalistas, na justa medida em que o sistema de apropriação e de reprodução da propriedade privada exige algum tipo de controle dos processos de trabalho (necessidade de assegurar e estimular a produçăo de excedentes econômicos). Em função disso, as formas de produção capitalistas delimitam o espaço das alternativas de gestão que lhes são "adequadas" e que só podem ser de tipo heterônomo, enquanto a autogestão é justamente seu antípoda. ${ }^{4}$

\section{capitalismo social prioriza os stakeholders em relaçáo aos shareholders, acrescentando à lógica do lucro as determinações da responsabilidade sociál ou da função ética e social da propriedade.}

Simetricamente, formas co-gestionárias (gestão paritária entre gestores e trabalhadores), a exemplo doskibutzim israelenses ou das cooperativas rurais brasileiras, remetem a formas de produção segmentárias e não-classistas, também incompatíveis com as formas de produção capitalistas. ${ }^{5}$

Isto significa que as formas de produção demarcam um campo de "possíveis históricos" que não podem ser impunemente ultrapassados sem afetar estruturalmente as relações de propriedade e de trabalho que as alicerçam.

De outra parte, existem também afinidades eletivas entre formas de produção e formas de pensamento (ideologias). A título de ilustração: ideologias libertárias do tipo anarquista ou socialista (democrática) não são compatíveis com empresas capitalistas, assim como não o são as ideologias totalitárias do tipo fascista ou comunista, uma vez que tais ideologias li-
4. GUILHERM, A, BOURDET, $Y$. Autogestão: uma mudança radical. Rio de Janeiro: Zahar, 1976.

5. Embara a Alemanha batize sua "democracia industrial" de co" gestão, parece-nos que o rótulo supera a realidade dos fatos trata-se de um sistema de gestão participativa bastante avançado, mas que não chega a estabelecer uma efetiva paridade entre trabalhadores e gestores. Ver SROUR, R. H. Op. cit. 
6. TAYLOR, F. W. Principios de administraçāo cientifica. São Paulo: Atlas, 1987.

7. SROUR, R. H. Classes, regimes, Ideologias. São Paulo: Ática, 1987.

8. Idem, ibidem.

9. BRAVERMAN, H. Trabalhoe capital monopolista. Rio de Janeiro: Zahar, 1977.

10. BRUNO, L., SACCARDO, C. (coord.). Organizaçāo, trabalho e tecnologia. São Paulo: Atlas, 1986. bertárias e totalitárias opõem-se frontalmente e advogam cabalmente (pelo menos em seus textos fundadores) o fim da propriedade privada dos meios de produção. Mais adiante procuraremos indicar conexões pertinentes entre ideologias (que são as gramáticas das culturas organizacionais) e formas de gestão.

\section{HETERONOMIA VERSUS AUTONOMIA}

Todas as formas de produção classistas implicam formas de gestão heterônomas, isto é, formas de gestão que asseguram a presença de gestores no controle do processo de produção. A clássica divisão técnica do trabalho taylorista que teoriza a nítida separação entre o trabalho de concepção e de controle (a cargo de gestores e especialistas) e o trabalho de execução (a cargo de trabalhadores) é emblemática nesse sentido. ${ }^{6}$

Outra forma de gestão heterônoma bastante conhecida, em que os gestores (feitores) são tudo e os trabalhadores ficam reduzidos à força bruta de trabalho, está bem representada na forma de produção latifundiária escravista ou na escravidão industrial dos campos de concentração de propriedade corporativa.

Há outras heteronomias menos marcantes, ainda que efetivas, pelo fato de os trabalhadores dișporem de qualificação técnica e de partilharem o controle do processo de trabalho com gestores. Tratase, por exemplo, das formas latifundiárias do colonato e da parceria, e das formas feudais, além das oficinas artesanais ou da "manufatura capitalista" (forma de produção transitória anterior à Revolução Industrial, na qual se instala o processo de parcelamento das tarefas).

A contrapelo, formas autônomas de gestão, além das comunidades anarquistas e dos mutirões já citados, encontram-se nas formas de produção comunais, participacionistas e patriarcais (pequena produção familiar), assim como nas formas comunitárias.?

\section{OS MODOS DE GESTÃO}

É possível demarcar quatro modos de gestão (conceito genérico que abrange várias formas de gestão): o totalitário e o autoritário, o liberal e o democrático. ${ }^{8} \mathrm{Os}$ dois primeiros remetem a uma matriz de "poder de exceção", enquanto os dois últimos repousam numa matriz de "poder de direito". Seu âmbito seria tanto macroestrutural (nível da sociedade inclusiva), como microestrutural (nível das organizações concretas).

No caso das relações de propriedade capitalistas, dois modos de gestão apenas são compatíveis com elas, uma vez que não se chocam com suas exigências estruturais de controle privado do trabalho assalariado (trabalhadores livres destituídos de meios de produção). São eles: o modo de gestão autoritário (amplamente dominante) e o modo de gestão liberal, bastante visível em empresas de serviços.

O modo de gestão autoritário articulase com a base técnica da Primeira e da Segunda Revolução Industrial, em que a maquinofatura substitui o trabalho braçal pela máquina, mas o faz convertendo a força de trabalho em prolongamento das máquinas-ferramenta, num processamento parcelado e rotineiro. ${ }^{9} \mathrm{O}$ modo de gestão liberal emparelha-se com a Terceira Revolução Industrial, em que as tarefas manuais repetitivas são substituídas por autômatos e as rotinas de cálculo são simplificadas pelo uso de equipamentos informatizados, de sorte que a força de trabalho fica liberada para funções de concepção e criação, ${ }^{10}$ o que exige dela qualificação técnica e participação em equipes multifuncionais. Em contrapartida, o desemprego estrutural a atinge, apontando dialeticamente para as possibilidades da conquista de menores jornadas de trabalho e para o desfrute de mais lazer.

Por sua vez, o modo de gestão totalitário parece ter tido sucesso com a base técnica mecânica e eletromecânica (Primeira e Segunda Revolução Industrial), e não se dispõe ainda de casos históricos de sua compatibilidade com a Terceira Revolução Industrial. Ele opera, assim como o modo de gestão democrático, num campo demarcado por relações econômicas que não são capitalistas ou o são subsidiariamente.

De fato, o modo de gestão totalitário se inscreve, de maneira típica, no bojo de economias de comando, em que o Estado liquida o mercado e se apropria de forma monopólica dos meios de produção material e de serviços (contemporaneamente, atualiza relações de propriedade esta- 
tistas-corporativistas). Em contraposiçăo, o modo de gestão democrático convive com economias de mercado que abrigam formas plurais de propriedade: propriedade capitalista, cooperativista, pública, comunitária, patriarcal, comunal etc. Tem condiçōes de manter o mercado tutelado (socialismo de mercado, nacional-desenvolvimentismo), em que o Estado dispŏe de um forte arsenal de organismos e de mecanismos de intervenção sobre o mercado, ou ainda pode, segundo as teses anarquistas, regular as trocas econômicas através de um pacto federativo entre comunidades livres.

Embora os conceitos de modose formas de gestão sejam conceitos de cunho político, imbricam-se neles as ideologias políticas e as ideologias econômicas, como se fossem verdadeiras argamassas. Ou seja, a dimensão simbólica apresenta-se como indissociável das operações de gestão.

Ademais, o corpo teórico aqui utilizado funda sua pertinência nos processos histórico-sociais em curso no mundo contemporâneo. Vale dizer, a história atual fornece a matéria-prima cujas regularidades são processadas a partir de um dispositivo teórico aplicável a todas as sociedades humanas, mas que, no caso, está se restringindo à especificidade dos sistemas mundiais capitalistas e socialistaestatista. Donde o apelo

\begin{tabular}{|c|c|c|c|c|}
\hline $\begin{array}{l}\text { Moló de } \\
\text { gestão }\end{array}$ & $\begin{array}{l}\text { Forma de } \\
\text { gestáo }\end{array}$ & $\begin{array}{l}\text { Ideologia } \\
\text { polfitica, }\end{array}$ & $\begin{array}{l}\text { lefeologia } \\
\text { eçenómica }\end{array}$ & $\begin{array}{l}\text { Concepçăo } \\
\text { de economia }\end{array}$ \\
\hline totalitário & $\begin{array}{l}\text { missianáría } \\
\text { custodial }\end{array}$ & $\begin{array}{l}\text { comunista } \\
\text { fascista }\end{array}$ & $\begin{array}{l}\text { estatista- } \\
\text { corporativista }\end{array}$ & $\begin{array}{l}\text { economia de } \\
\text { comando } \\
\text { (planejamento } \\
\text { central) }\end{array}$ \\
\hline autoritáríp & $\begin{array}{l}\text { ortodoxa } \\
\text { clássica }\end{array}$ & $\begin{array}{l}\text { tradicionalista } \\
\text { conservadora }\end{array}$ & neoliberal & $\begin{array}{l}\text { mercado fivre } \\
\text { (Estado } \\
\text { mínimo) }\end{array}$ \\
\hline liberal & $\begin{array}{l}\text { pluralista } \\
\text { reformista }\end{array}$ & $\begin{array}{l}\text { liberal } \\
\text { social- } \\
\text { democrata }\end{array}$ & social-liberal & $\begin{array}{l}\text { mercado } \\
\text { regulado } \\
\text { (planejamento } \\
\text { indicativo) }\end{array}$ \\
\hline democrảtico & $\begin{array}{l}\text { co-gestionária } \\
\text { aulo-gestioná: } \\
\text { ria }\end{array}$ & $\begin{array}{l}\text { socialista } \\
\text { anarquista. }\end{array}$ & $\begin{array}{l}\text { socialista de } \\
\text { mercado }\end{array}$ & $\begin{array}{l}\text { mercado } \\
\text { tutelado ou } \\
\text { pacto } \\
\text { comunitário }\end{array}$ \\
\hline
\end{tabular}
aos ideários contemporâneos, em íntima conexão com as formas de exercício do poder (regimes políticos) incidentes no período. Procura-se assim saturar os conceitos historicamente, sem desembocar em generalizações que alguns poucos "casos" ofereceriam, de forma impressionista.

Tal démarche permite captar homologias estruturais: por exemplo, o modo de produção "capitalista excludente" e o modo de produção corporativista (socialista-estatista ou fascista) afinam-se com o poder de exceção e com a matriz autoritária de pensamento político; o modo de produção "capitalista social" e o modo de produção cooperativista afinam-se com o poder de direito e com a matriz libertária de pensamento político ${ }^{11}$ (ver quadro 1).

\begin{tabular}{|c|c|c|}
\hline $\begin{array}{l}\text { Matrizsde } \\
\text { poder }\end{array}$ & $\begin{array}{l}\text { Mathiz de } \\
\text { pensamento político }\end{array}$ & $\begin{array}{l}\text { Modode } \\
\text { praducão }\end{array}$ \\
\hline de exceção & autoritária & $\begin{array}{c}\text { capitalista excludente } \\
\text { corporativista }\end{array}$ \\
\hline de direito & libertária & $\begin{array}{c}\text { capitalista social } \\
\text { cooperativista }\end{array}$ \\
\hline
\end{tabular}

De outro lado, modos de gestăo, formas de gestão, ideologias políticas e econômicas, e concepções de economia (pelo menos no Brasil) estabelecem vinculações eletivas que o quadro 2 pretende retratar.

É interessante notar que as ideologias econômicas podem ser agrupadas e cindidas em duas matrizes de pensamento econômico: uma matriz dirigista (estatismo-corporativista, socialismo de mercado, nacional-desenvolvimentismo, pacto entre comunidades livres federadas) e uma matriz libcral (neoliberalismo e socialliberalismo). Enquanto a primeira converte o Estado (ou o pacto comunitário) em demiurgo, a segunda supõe a redução da presença do Estado na economia e abomina intervencionismos que violen-
11. SROUR, R. H. Principios de administração... Op. cit. 
tem o mercado e o normalizem em excesso.

Agora, em nível microestrutural, parece lícito fornecer algumas ilustrações empíricas de uma tipologia política das organizações. Por excmplo: organizações totalitárias encontram-se nas penitenciárias, nos manicômios, nos orfanatos, nos reformatórios, nos conventos, nos internatos, nas praças de guerra, nos campos de trabalho forçado e nas seitas religiosas milenaristas.

Ilustrações de organizaçōes autoritárias encontram-se nos canteiros de obras, nas empresas mineradoras, na maior parte dos órgãos públicos e das empresas estatais e das empresas privadas brasileiras.

Ilustrações de organizações liberais encontram-se $\mathrm{em}$ agências de publicidade e nos meios de comunicação, em escritórios de advocacia e em associações profissionais não burocratizadas, em empresas de consultoria e de informática, em centros universitários e de pesquisa.

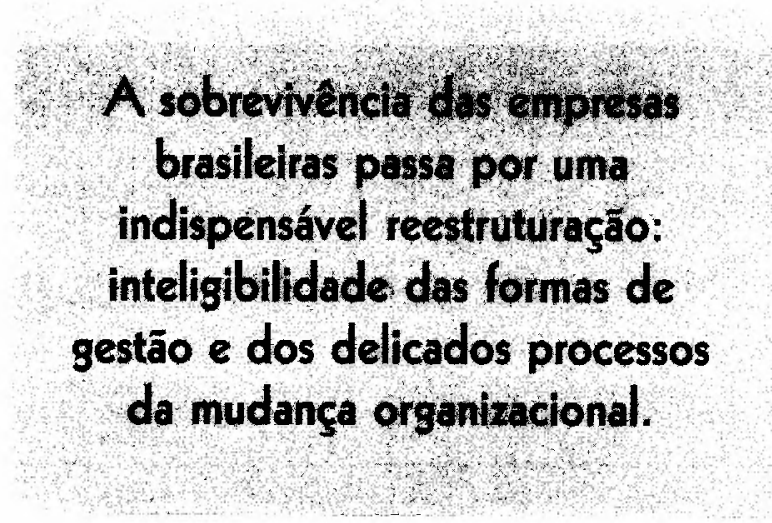

Ilustrações de organizaçōes democráticas encontram-se em movimentos sociais, cooperativas de trabalho, blocos de carnaval, comunidades rurais, mutirões, bem como nas chamadas organizações alternativas em que os coletivos incorporam praticamente a função gestora.

Assim, cada modo de gestão ou regime político e, dentro dele, cada forma de gestão, constitui uma articulação de relações de poder com relações de saber, articulação esta que se vê sobredeterminada por uma lógica econômica que the confere forte consistência interna, tanto do ponto de vista teórico quanto em termos de mecanismos de reprodução. Além do mais, e para não incorrermos em simplificações, vale salientar que cada forma de gestão sc desdobra em vertentes ou modalidades. $\mathrm{O}$ nível de "saturação histórica" ou de concretude ganha desta maneira ampla densidade.

Retomando os passos, diríamos: o conceito mais abrangente é o de modo de gestão; em cada modo de gestão cocxistem algumas formas de gestão que, por sua vez, abrigam modalidades de gestão. Fstas últimas atualizam-se concretamente em empresas reais que apresentam uma configuração modal, ainda que possam integrar, de maneira bastante complexa, uma multiplicidade de formas e de modalidades de gestão. Isto ocorre em função da variedade estrutural de seus setores componentes, dos tipos de tecnologia empregados c da formação profissional dos trabalhadores e gestores que nelas estão cngajados.

Cada forma de gestão debulha modalidades históricas de gestão, uma vez que expressa as características peculiares das sociedades em que se insere. No caso brasileiro, por exemplo, poderíamos falar tentativamente de modalidades autocrática, "feudalizada" e restauradora (na forma de gestão ortodoxa) e cm modalidades paternalista, oligárquica e renovadora (na forma de gestão clássica).

Isto nos faculta navegar do mais abstrato ao mais concreto, sem dogmatismo e sem relativismo exacerbado. Mais ainda, permite-nos transitar dos conceitos abstratos e gerais (modos) aos conceitos de menor envergadura, abstratos e específicos (formas c modalidades de gestão). Para desembocarmos, finalmente, em conceitos singulares que nomeiam o empírico. Por exemplo, na caracterização das particularidades de empresas concretas, tais como a Rhodia brasileira, a Petrobrás, a Belgo-Mineira, o Banco do Brasil, a Gessy Lever, ou a Volvo em Kalmar, ou ainda a Microsoft Corporation e a Xerox nos EUA.

Longe de qualquer empiricismo, isto nos permite cultivar a flexibilidade conceitual - no nível das configurações histórico-concretas - investindo no real o dispositivo teórico que é explicativo e fundante. 


\section{O EMPENHO EM MUDAR}

A forma de gestão não se confunde ou coincide necessariamente com o discurso da alta direção, nem se reduz a uma mera generalização empírica de alguns "casos" investigados. Trata-se de um conceito com adequado grau de abstração, mas também com ampla saturação histórica. Sem ele, corre-se o risco de derrapar na penumbra, tomando sombras por realidades.

Afinal, quantos programas de mudanças organizacionais dormitam o sono dos justos nas gavetas das diretorias? Alguns porque propõem projetos que afetam a "coalizão dominante", fiando-se ao pé da letra na retórica participacionista dos altos gestores. E, neste caso, acabam ilustrando sem querer ou sem saber, o velho descompasso entre o "país formal" e o "país real", ou a defasagem entre o fraseado up-to-date e a realidade palpável do jogo dos interesses. Outros programas fallham porque acreditam nas virtudes das boas intenções (tecnocráticas) e não administram as resistências sorrateiras daqueles agentes que as mudanças afetam. Alguns últimos, por fim, não chegam a termo por não percebcrem que as mudanças, não obstante tenham um conteúdo intrínseco louvável, não guardam congruência com a forma de gestão vigente. Pagam tributo ao clássico paradoxo das consequiências, em que as próprias mudanças criam novas disfunções que as põem a perder. Basta citar o exemplo de muitos processos de qualidade, intempestivamente introduzidos em empresas cujas formas de gestão são verticalistas e autoritárias, e que acabam gerando dissonância cognitiva e inúmeros efeitos colaterais. Ficam então responsabilizados, a título de bodes expiatórios, a "cultura brasileira" ou o "caráter" esperto e negativista dos brasileiros...

Agora - e por mero exercício especulativo -, imaginemos que uma direção autocrática prelenda implantar, por decreto, uma estratégia incompatível com a forma de gestão em vigor, o que teremos? Muito provavelmente uma crise ao estilo soviético. Porque querer obter dos funcionários, por exemplo, capacidade criativa
A inexistência de cidadania no seio das empresas, com todas as suas seqüelas de impedimentos que amordaçam iniciativas e criatividade, constitui sério empecilho para a consecução de práticas gestionárias mais avançadas.

em ambiente politicamente fechado, sem o oxigênio libertário da polêmica e das críticas, sem o cultivo das diferenças ou o reconhecimento de sua legitimidade, é sonhar acordado. Como alcançar altos índices de produtividade e de desempenho no manejo das novas tecnologias, com um pessoal que não dispõe de adequada escolarização, padece do medo de errar, curva-se em seu conformismo e recolhese na sua passividade de espectador? $O$ funcionário que não se percebe nem age como parte integrante da organização não pode trazer contribuições que transcendam o cumprimento das próprias rotinas. Ora, as novas tecnologias demandam, em primeira mäo, alteração radical do layout da produção, capacitação profissional, assunção de riscos, iniciativa do pessoal debaixo e trabalho realizado por equipes semi-autônomas ou, pelos menos, por trabalhadores autonomizados ("profissionais"),

De maneira que a utilidade de uma análise científica das várias formas de gestão, no contexto da empresa capitalista, começa residindo na vantagem de desmistificar os discursos prescritivos e doutrinários que fazem as delícias das publicações especializadas do management. Prossegue abrindo um caminho prático para intervençóes organizacionais competentes. Porque cuida de estabelecer os liames "orgânicos" entre o tipo específico de propriedade e as respectivas relações de poder e de saber.

\section{AS FORMAS DE GESTÃO CAPITALISTAS}

Muitos vetores estruturais caracterizam e diferenciam cada forma de gestão. Nos 
estreitos limites desse artigo, não caberia fazer uma análise exaustiva de cada um deles, nem desenvolver uma fundamentação teórica e empírica de sua pertinência. De maneira que serão citados, a títu-

\begin{tabular}{|c|c|c|c|c|}
\hline $\begin{array}{l}\text { Forma de } \\
\text { gestão }\end{array}$ & $\begin{array}{l}\text { Regíme } \\
\text { politico }\end{array}$ & $\begin{array}{l}\text { Ideologia } \\
\text { política }\end{array}$ & $\begin{array}{l}\text { Netáfora } \\
\text { (tormato) }\end{array}$ & Rituals \\
\hline ortodoxa & autoritário & tradicionalista & $\begin{array}{l}\text { repartição } \\
\text { pública }\end{array}$ & $\begin{array}{l}\text { parada } \\
\text { mifitar } \\
\text { (fanfarra } \\
\text { marcial) }\end{array}$ \\
\hline clássica & autoritário & conservadora & $\begin{array}{l}\text { loja de } \\
\text { departamentos }\end{array}$ & $\begin{array}{l}\text { procissão } \\
\text { religiosa } \\
\text { (orquestra } \\
\text { sintônica) }\end{array}$ \\
\hline pluralista & liberal & liberal & $\begin{array}{l}\text { agência de } \\
\text { publicidade }\end{array}$ & $\begin{array}{l}\text { desfíe } \\
\text { carnavalesco } \\
\text { (banda de } \\
\text { jazz) }\end{array}$ \\
\hline reformista & libera! & $\begin{array}{l}\text { social- } \\
\text { democrata }\end{array}$ & $\begin{array}{l}\text { centro de } \\
\text { pesquisa }\end{array}$ & $\begin{array}{l}\text { passeata } \\
\text { (roda de } \\
\text { samba) }\end{array}$ \\
\hline
\end{tabular}

lo de pistas, os vetores principais e seus caracteres diferenciadores, tão somente para as formas de gestão detectadas em empresas capitalistas (forma de gestão ortodoxa, clássica, pluralista e reformista):

- os tipos de relações sociais que se estabelecem no seio das organizações: relações de dependência ou de interdependência;

- os modos de exercitar o poder, se autoritário ou liberal, e das formas que assumem: imperativo, delegatório, consultivo, deliberativo;

- as formas de mando que gestores adotam nos processos de trabalho: diretividade ampla, diretividade restrita, partilha restrita, partilha ampla;

- as formas que assumem os processos de tomada de decisão: centralizada, desconcentrada, descentralizada, multilateral;

- as diferentes filosofias de pessoal: enquadramento, transigência, entendimento, parceria;

- as diferentes concepções dos conflitos, tratando-os como: eventos indesejáveis, desvios à normalidade, eventos normais, processos úteis;

- o tipo predominante de divisão técnica do trabalho: parcelamento de tarefas, Iinha de montagem, células de produção, equipes semi-autônomas;

- a filosofia de gestão: produtivista, concessiva, integradora, participativa;

- o sistema de avaliação de desempenho, priorizando: a dedicação, a adaptação, a qualificação, a competência;

- o sistema de controle: por pressões e ameaças, por ciclotimias e sanções, por desafios e incentivos, por emulação coletiva;

- o sistema de comunicação configurado: em linha, em estrela, em roda, em rede.

A título de ilustração, e no intuito de produzir nos leitores algum tipo de insight, compararemos agora, no quadro 3, as formas de gestão capitalistas visíveis no cenário brasileiro com: os regimes políticos e as ideologias políticas com os quais elas mantêm maiores afinidades eletivas; as metáforas sobre seus formatos emblemáticos e os rituais com os quais mais elas se assemelham.

A rigidez da repartição pública e da parada militar, fortemente hierarquizadas e amplamente verticalistas em seus sistemas de poder, produz "peças musicais" sofríveis que a fanfarra marcial ilustra. $\mathrm{O}$ bom senso e o equilíbrio da loja de departamentos e da procissão religiosa, moderadamente autoritárias, produzem uma "sonoridade" particularmente afinada, à semelhança da orquestra sinfônica cujos instrumentistas tocam pautados pelas partituras e pela batuta do maestro. Ambas as metáforas pertencem ao modo de produção que denominamos "capitalista excludente"

Em contrapartida, a maleabilidade liberal da agência de publicidade e do desfile carnavalesco, com suas iniciativas próprias e com o envolvimento espontâneo de seus integrantes, lembra a flexibilidade da banda de jazz e a riqueza das improvisações que seus músicos realizam em torno de um tema musical. Isto é ainda mais pronunciado na versatilidade do centro de pesquisa ou da passeata, em que a relativa autonomia dos componentes estriba o trabalho de equipe. Esse formato encontra exemplo à altura na roda de samba, com sua excepcional criatividade e sua polivalência no manejo dos instrumentos. Ambas as metáforas remetem 
ao modo de produção que denominamos "capitalista social".

\section{SERIA A CULTURA BRASILEIRA UM EMPECILHO PARA A COMPETITIVIDADE?}

Uma indagação de grande pertinência nos remete, finalmente, a uma desagradável constatação: por que as aplicações das best practices (Just-in-Time, Zero Defect, CCQ, TQC, kanban, kaisen, Administração por Diretrizes etc.) têm sofrido percalços no Brasil, quando não fracassos? Estaria a cultura local, à socapa, minando ou inviabilizando a introdução de tais técnicas ou sistemas? Se essa última hipótese fosse verdadeira, toda reestruturação organizacional estaria fadada ao desastre.

Um encaminhamento alternativo consistiria em procurar possíveis incompatibilidades entre certas best practices e dadas formas e modalidades de gestão, tendo em vista a especificidade histórica da sociedade brasileira. Pois, embora as formas de gestão capitalistas sejam universais, suas modalidades assumem feições peculiares segundo os países. Não se pode negar, de fato, que o capitalismo periférico brasileiro, com seus caracteres cartoriais, protecionistas e oligopolistas, imprime a todas as organizações suas marcas indeléveis. Mas poderia ele condenar a absorção de tecnologias ou a adoção de formas de gestão já testadas no Primeiro Mundo? De modo algum. Se assim fosse, o Brasil não teria realizado uma Revolução Industrial em 40 anos.

Por isso mesmo, aliás, parece lícito inverter a indagação e apreender as compatibilidades entre as formas de gestão em vigor no país e as exigências postas por determinadas práticas importadas. Poder- se-ia então descobrir o que caberia redefinir para que as mudanças fossem operantes.

Com efeito, nem o peso das relações pessoais (parentesco, compadrio, vizinhança, amizade, coleguismo) que se traduzem organizacionalmente em redes informais de poder; nem a falta de assertividade nas relações interpessoais, aliada a tendências em simular a evitação de conflitos e confrontos; nem o personalismo e a forte preocupação em controlar a incerteza, com suas implicações sobre os subordinados (conformismo, dificuldade em assumir riscos com a conseqüente transferência de responsabilidades, negativismo); nem a diferenciação hierarquizadora entre "gente distinta" (os agentes pertencentes às categorias sociais privilegiadas) e "gente simples" (os pés-rapado, os joões-ninguém que participam do mundo subalterno dos discriminados); nem o jeito afetuoso, íntimo, descontraído, amável, alegre de relacionarse; nem o desrespeito às normas universais na procura ansiosa de um tratamento personalizado (o famoso jeitinho); e nem mesmo as práticas "espertas" inspiradas por uma ética do oportunismo convertem-se substantivamente, como todo o resto, em fatores impeditivos para a instalação de altos padrões de eficiência e de produtividade. Quando muito, esses fatores impõem limitações, requerem cuidados e coibições, exigem adaptações.

Porém, a inexistência de cidadania no seio das empresas, com todas as suas seqüelas de impedimentos que amordaçam iniciativas e criatividade, que esterilizam em boa medida as possibilidades de perceber-se como parte integrante da empresa, isso sim constitui sério empecilho para a consecução de 
12. WELLINS, R. S. BYHAM, W. C., WILSON, J. M. Empowered team. San Francisco: JosseyBass, 1991. práticas gestionárias mais avançadas.

Tal óbice, contudo, remete à questão das formas de gestão, e não genericamente à "cultura brasileira". Afinal, a questão que nos ocupa diz respeito às formas de regular atividades em empresas que operam tanto no mercado formal de trabalho como no âmbito da legalidade institucional, empresas que se pretendem racionalmente capitalistas ou, pelo menos, que deverão tender a sê-lo se não quiserem deperecer.

No Brasil, o fato de as tecnologias de produção em uso serem ainda predominantemente de produção em massa, em contraste com tecnologias de produção flexível e de alto valor agregado, faz com que os controles sobre a força de trabalho assumam caráter político. Temos estratégias de "disciplinamento" da força de trabalho e não de "consentimento", a exemplo do que acontece nas formas de gestão liberais em que o controle, ao ser internalizado pelos agentes sociais, se processa simbolicamente. De modo que o mecanismo de reprodução organizacional que detém a supremacia, no Brasil, é mais coator (poder e legalidade) do que persuasivo (saber e legitimidade).

De modo contrastante, a problemática simbólico-cultural tão em evidência no Primeiro Mundo faz sentido naquele contexto, à medida que o modo de organizar os processos produtivos tende a não mais ser o de privilegiar a repetição rotineira, o parcelamento simplificador e o trabalho padronizado. Neste quadro, os trabalhadores são capacitados para a polivalência e a multifuncionalidade, respondem por um segmento da produção ou por um produto por inteiro, além de serem avaliados por resultados não só individuais, mas sobretudo coletivos. Em suma, os executantes compõem equipes semiautônomas que incorporam muitos dos atuais micropoderes gerenciais, o que lhes confere autoridade política e "posse" sobre seu próprio processo de trabalho (empowerment). ${ }^{12}$ Isso exige da força de trabalho, é claro, mais qualificação técnica e maior nível de responsabilidade. Eis a configuração característica do processo de produção da Terceira Revolução Industrial, que vai, aos poucos, disseminando-se.

No Brasil, todavia, a força de trabalho ainda é abundante, desqualificada e intercambiável ("descartável") e os processos técnicos filiam-se à Segunda Revolução Industrial, no velho ramerrão alienante de tipo taylorista-fordista.

São esses os fundamentos econômicos do domínio do "político" nas formas de gestão brasileiras (ortodoxa e clássica), de corte autoritário, ao invés do "simbólico" que predomina nas formas de gestão liberais (pluralista e reformista), em ascensão no Primeiro Mundo.

Assim, por ser autoritária, discriminatória, envergonhadamente racista, patriarcal, hierarquizada, centralizadora, predatória e desperdiçadora, além de tecnologicamente "atrasada", a sociedade brasileira repercute nas organizações que tendem a reproduzi-la capilarmente. Nem por isso, todavia, o desafio da implantação de formas de gestão mais competitivas torna-se insuperável.

Paradoxo? Absolutamente não, porque nem mesmo a doutrina católica tradicional que santifica a pobreza e estigmatiza o lucro, colocando de certa forma a acumulação de riquezas no índex - em contraste com a doutrina calvinista da predestinação (decretum horribile) que sacraliza as virtudes da diligência, da poupança e do enriquecimento -, nem mesmo esse catolicismo constituiu no passado e constitui hoje barreira intransponível. $\mathrm{O}$ sucesso da França e da Itália católicas atestam com brilhantismo a viabilidade do projeto de criação de um "capitalismo social", no bojo de uma Terceira Revolução Industrial, a despeito de quaisquer padrões culturais latinos.

Até no Brasil imperial do latifúndio escravista, quando o trabalho era aviltante e mais se prezava o ócio do que o negócio, uma releitura das formas de gestão foi feita nas casas comissárias (comercializadoras do café do Vale do Paraíba) e nas chamadas "fábricas nacionais" que usufruíram, no século XIX, da isenção de tarifas para a importação de matérias-primas para seu consumo. $\mathrm{E}$ isso para não falarmos dos surtos industrializantes posteriores (Primeira Guerra Mundial, década de 30) e do arranque decisivo da grande indústria na segunda metade do século XX. De fato, o controle da força de trabalho deixou de estar nas mãos dos velhos feitores totalitários dos engenhos de açúcar para ficar 
a cargo de gestores que eram chefes autoritários.

Isso permite lançar luz sobre um fato notável e já consagrado: as organizações são coletividades que têm padrōes próprios e são movidas por estímulos que conseguem, em certa medida, autonomizá-las em relação à sociedade inclusiva. Sem ter-se clareza quanto a isso, nāo é possível explicar a extraordinária variedade de organizações existentes no Brasil: a Igreja Católica e os dois partidos comunistas, as comunidades rurais anarquistas e as organizações tradicionalistas como a TFP (Tradição, Família e Propriedade) e o movimento monarquista (Casa de Vassouras), as tendas de umbanda e os terreiros de candomblé, os movimentos sociais defensores da ecologia, das mulheres, dos negros, dos homossexuais, dos menores de rua ou dos idosos, as associaçōes profissionais e as sociedades de bairro, os clubes de serviço e os blocos de carnaval, as diferentes centrais sindicais e os sindicatos de orientação pelega, reivindicadora ou "combativa", as empresas estatais "de ponta" e as que não passam de modorrentas repartiçöes públicas, os centros de pesquisa avançada e as penitenciárias totalitárias, as lojas maçônicas e as cooperativas de consumo, as bancas de jogo do bicho e o Comando Vermelho, os clubes de futebol de várzea e os esquadrões de extermínio, os centros espíritas e as seitas pentecostalistas, as gangues de carecas neonazistas e as "galeras" de funkeiros suburbanos, as quadrilhas de traficantes de droga e as escolas de samba, as produtoras de vídeo e as agências de publicidade premiadas internacionalmente, as organizações alternativas e as comunidades eclesiais de base, as Santas Casas da Misericórdia e a multidão de empresas autoritárias e paternalistas, e assim por diante.

O Brasil dispõe, sim, de uma miríade riquíssima de organizações que atualizam praticamente todos os "possíveis históricos" contemporâneos e que atestam empiricamente a plasticidade das formas de gestão.

Vale a pena então questionar as insuficiências do raciocínio circular, de cunho eminentemente ideológico, proje-
As urgências que as empresas brasileiras sofrem são de ordem organizacional. Apontam para a necessidade de debruçar-se sobre um instrumental que permita incorporar, criativamente, as experiências que foram bemsucedidas nos centros dinâmicos do capitalismo mundial. tando para as calendas gregas a obtenção de padrões superiores de desempenho nas empresas brasileiras: expectativa que só será satisfeita se o "povo for educado" ou se for extirpada a "sem-vergonhice" dos brasileiros. Pois tal raciocínio não fere a questão central e que diz respeito ao controle das condições ambientais. Afinal, quem não se espanta com o compor tamento ordeiro dos usuários do metrô de São Paulo, ao saber que esses mesmos usuários, instantes antes de embarcar, baldearam de uma estação de trens suburbanos, com vidros quebrados, "surfistas" suicidas no teto e pingentes, portas que não fecham, lixo no chão e composições pichadas com sprays coloridos? Ou seja: o que importa não é tăo somcntc a "educação do povo", mas, isso sim, a forma como se gerencia o transporte, o controle das condições ambientais; afinal, os agentes sociais respondem aos estímulos $\mathrm{e}$ aos condicionamentos do ambiente em que se movem. Se tratados como gado, "mugem"; se tratados como cidadãos, agem com responsabilidade.

Em suma, as urgências que as empresas brasileiras sofrem são de ordem organizacional. Apontam para a necessidade de debruçar-se sobre um instrumental que permita incorporar, criativamente, as experiências que foram bem-sucedidas nos centros dinâmicos do capitalismo mundial. E ensinam que a chave de decifração das dificuldades para realizar mudanças é menos cultural do que política, embora a dimensão cultural deva ser ampla e competentemente administrada. Pois, desde logo, cumpre mudar as formas de gestão que inibem as empresas a competir de forma inovadora no mercado planetário. $\square$ 